\title{
Article \\ Photorespiration Alleviates Photoinhibition of Photosystem I under Fluctuating Light in Tomato
}

\author{
Qi Shi ${ }^{1,2,+}\left(\mathbb{C}\right.$, Hu Sun ${ }^{1,2,+}$, Stefan Timm ${ }^{3}{ }^{(0)}$, Shibao Zhang ${ }^{1}$ and Wei Huang ${ }^{1, *(1)}$ \\ 1 Kunming Institute of Botany, Chinese Academy of Sciences, Kunming 650201, China; \\ shiqi@mail.kib.ac.cn (Q.S.); sunhu19@mails.ucas.ac.cn (H.S.); sbzhang@mail.kib.ac.cn (S.Z.) \\ 2 University of Chinese Academy of Sciences, Beijing 100049, China \\ 3 Plant Physiology Department, University of Rostock, D-18051 Rostock, Germany; stefan.timm@uni-rostock.de \\ * Correspondence: huangwei@mail.kib.ac.cn \\ + These authors contributed equally to this work.
}

check for updates

Citation: Shi, Q.; Sun, H.; Timm, S.; Zhang, S.; Huang, W.

Photorespiration Alleviates Photoinhibition of Photosystem I under Fluctuating Light in Tomato. Plants 2022, 11, 195. https:/ / doi.org/10.3390/plants11020195

Academic Editors: Pirjo Mäkelä, Mercè Llugany, Peter A. Roussos and Mumtaz Cheema

Received: 4 December 2021 Accepted: 31 December 2021 Published: 12 January 2022

Publisher's Note: MDPI stays neutral with regard to jurisdictional claims in published maps and institutional affiliations.

Copyright: (C) 2022 by the authors. Licensee MDPI, Basel, Switzerland. This article is an open access article distributed under the terms and conditions of the Creative Commons Attribution (CC BY) license (https:// creativecommons.org/licenses/by/ $4.0 /)$.

\begin{abstract}
Fluctuating light (FL) is a typical natural light stress that can cause photodamage to photosystem I (PSI). However, the effect of growth light on FL-induced PSI photoinhibition remains controversial. Plants grown under high light enhance photorespiration to sustain photosynthesis, but the contribution of photorespiration to PSI photoprotection under FL is largely unknown. In this study, we examined the photosynthetic performance under FL in tomato (Lycopersicon esculentum) plants grown under high light (HL-plants) and moderate light (ML-plants). After an abrupt increase in illumination, the over-reduction of PSI was lowered in HL-plants, resulting in a lower FL-induced PSI photoinhibition. HL-plants displayed higher capacities for $\mathrm{CO}_{2}$ fixation and photorespiration than ML-plants. Within the first $60 \mathrm{~s}$ after transition from low to high light, PSII electron transport was much higher in HL-plants, but the gross $\mathrm{CO}_{2}$ assimilation rate showed no significant difference between them. Therefore, upon a sudden increase in illumination, the difference in PSII electron transport between HL- and ML-plants was not attributed to the Calvin-Benson cycle but was caused by the change in photorespiration. These results indicated that the higher photorespiration in HLplants enhanced the PSI electron sink downstream under FL, which mitigated the over-reduction of PSI and thus alleviated PSI photoinhibition under FL. Taking together, we here for the first time propose that photorespiration acts as a safety valve for PSI photoprotection under FL.
\end{abstract}

Keywords: photorespiration; cyclic electron flow; photoinhibition; photoprotection; photosystem I

\section{Introduction}

Growth light significantly affects photosynthetic performance in plants. Plants usually modulate their biochemical composition and leaf morphology to acclimate to the specific growth light conditions [1-5]. In general, plants grown under high light (HL-plants) have higher content of proteins and enzymes involving in photosynthetic electron flow and the Calvin-Benson cycle than plants grown under low light [6,7]. These characteristics favors the higher photosynthetic capacity in HL-plants. Concomitantly, the rate of ribulose1,5-bisphosphate (RuBP) oxygenation is also increased in HL-plants due to the higher ribulose-1,5-bisphosphate carboxylase/oxygenase (RubisCO) content [8]. Photorespiration is essential for the normal photosynthesis ambient $\mathrm{CO}_{2}$ and oxygen [9]. A stronger electron flow for photorespiration can protect photosystem II (PSII) by consuming the excess light energy $[9,10]$. However, the role of photorespiration in protecting photosystem I (PSI) under fluctuating light is not well known.

In natural habitats, leaves usually experience fluctuations of illumination owing to cloud, wind and changing leaf sun angle [11,12]. Under fluctuating light (FL), light absorption and PSII electron flow rapidly increased after an abrupt increase in light intensity $[13,14]$. Meanwhile, stomatal opening and the activation of the Calvin-Benson cycle 
have much slower kinetics [15-17]. Under such conditions, the reducing power in PSI cannot be immediately consumed by $\mathrm{CO}_{2}$ fixation. The resulting over-reduction of PSI triggers the donation of electrons to $\mathrm{O}_{2}$, producing reactive oxygen species in PSI $[12,18,19]$. Moreover, the antioxidant systems cannot immediately scavenge the reactive oxygen species [18]. Therefore, FL can give rise to PSI photoinhibition in many angiosperms [20-24]. Once PSI was damaged, $\mathrm{CO}_{2}$ assimilation and photoprotection were depressed, impairing the growth of plants [19,25-28].

To protect PSI under FL, plants have evolved several photoprotective strategies to optimize the PSI redox state [29-32]. In non-angiosperm plants, flavodiiron proteins mediate the photo-reduction of $\mathrm{O}_{2}$ and prevent PSI photoinhibition under FL, which is supplemented by cyclic electron flow (CEF) around PSI [29,32-35]. In angiosperms, the genes of flavodiiron proteins are lost and CEF is reserved to protect PSI under FL [19,36-38]. When light intensity increased abruptly, CEF activity rapidly increased to help the building up of trans-thylakoid proton gradient $(\Delta \mathrm{pH})$ [13]. Such CEF-dependent $\Delta \mathrm{pH}$ formation can down-regulate the oxidation of plastoquinone and thus controls electron flow to PSI at the cytochrome (Cyt) b6/f complex [39]. Furthermore, the CEF stimulation can provide additional ATP, facilitating the operation of the primary metabolism [40]. Consequently, CEF significantly alleviates PSI photoinhibition under FL at donor and acceptor side [21]. In previous studies, plants grown under low light were usually used to investigate the role of CEF in PSI photoprotection under FL, and found that the donor side regulation was the primary target of CEF [19-21,38]. However, the underlying mechanism of acceptor side regulation in dependence of CEF have not yet been clarified. Furthermore, how HL-plants protects PSI under FL is poorly understood.

By transitioning from low to high light, the full activation of the Calvin-Benson cycle requires several minutes [41]. Meanwhile, photorespiration has relatively faster kinetics, making photorespiration to be a major alternative sink [42]. During photorespiration, the oxygenation of RuBP consumes high amounts of NADPH, leading to an increase in $\mathrm{NADP}^{+} / \mathrm{NADPH}$ ratio, which facilities the electron transport from PSI to NADP ${ }^{+}$[43]. Under low $\mathrm{CO}_{2}$ concentration, the suppression of photorespiration by decreasing RubisCO content induced PSI over-reduction, and, thus accelerated PSI photoinhibition under excess light energy [44]. Therefore, photorespiration has the potential to promote the oxidation of PSI under excess light energy. The highly oxidation of PSI suppressed the donation of electrons from PSI to $\mathrm{O}_{2}$, and, thus prevented oxidative damage to PSI [45]. Accordingly, photorespiration might alleviate PSI photoinhibition under FL. We hypothesize that the increased capacity of photorespiration in HL-plants favors PSI photoprotection under FL.

In the present study, we measured gas exchange, chlorophyll fluorescence, P700 and electrochromic shift signals under fluctuating light for tomato plants grown under high light (HL-plants) and moderate light (ML-plants). Our aims were: (1) to compare the photosynthetic regulation under FL between HL- and ML-plants; (2) to assess the role of photorespiration in PSI photoprotection under FL. We found that FL induced a stronger PSI photoinhibition in ML-plants than HL-plants, and the higher capacity of photorespiration in HL-plants significantly alleviated FL-induced PSI photoinhibition.

\section{Materials and Methods}

\subsection{Plant Materials}

Tomato (Lycopersicon esculentum Miller cv. Hupishizi) plants were cultivated in full sunlight (HL-plants) or 40\% full sunlight (ML-plants). The day/night air temperatures were approximately $30 / 20^{\circ} \mathrm{C}$, and the maximum light intensity at noon for HL- and ML-plants were approximately 2000 and $800 \mu \mathrm{mol}$ photons $\mathrm{m}^{-2} \mathrm{~s}^{-1}$, respectively. All plants were grown with humus soil and any water and nutrient stress was prevented. After cultivation for one month, we used the canopy mature leaves for measurements. 


\subsection{Measurements of Gas Exchange and Photorespiration}

We used an open gas exchange system (LI-6400XT; Li-Cor Biosciences, Lincoln, NE, USA) to simultaneously measure gas exchange and chlorophyll fluorescence. After photosynthetic induction at $1500 \mu \mathrm{mol}$ photons $\mathrm{m}^{-2} \mathrm{~s}^{-1}$ and $400 \mu \mathrm{mol} \mathrm{mol}{ }^{-1} \mathrm{CO}_{2}$ concentration for $30 \mathrm{~min}$, the net $\mathrm{CO}_{2}$ assimilation rates $\left(A_{\mathrm{N}}\right)$ and chlorophyll fluorescence were recorded. The effective quantum yield of PSII photochemistry ( $\Phi_{\text {PSII }}$ ) was calculated as $\left(F_{m}{ }^{\prime}-F_{s}\right) / F_{m}{ }^{\prime}[46]$. The total electron transport rate through PSII ( PSII $\left._{\text {PS }}\right)$ as follows [47]

$$
J_{\mathrm{PSII}}=\Phi_{\mathrm{PSII}} \times \mathrm{PPFD} \times 0.84 \times 0.5
$$

The electron transport rate for photorespiration was calculated as follows [48]:

$$
J_{\mathrm{O}}=2 / 3 \times\left(J_{\mathrm{PSII}}-4\left(A_{\mathrm{N}}+R_{\mathrm{d}}\right)\right.
$$

where $R_{\mathrm{d}}$ was measured after incubation in darkness for $20 \mathrm{~min}$.

After adequate photosynthetic induction, the response of $\mathrm{CO}_{2}$ assimilation rate to incident intercellular $\mathrm{CO}_{2}$ concentration $\left(A / C_{\mathrm{i}}\right)$ curves were measured by decreasing the $\mathrm{CO}_{2}$ concentration to a lower limit of $50 \mu \mathrm{mol} \mathrm{mol}^{-1}$ and then increasing stepwise to an upper limit of $1500 \mu \mathrm{mol} \mathrm{mol}^{-1}$. For each $\mathrm{CO}_{2}$ concentration, photosynthetic measurement was completed in $3 \mathrm{~min}$. Using the $A / C_{\mathrm{i}}$ curves, the maximum rates of electron flux $\left(J_{\max }\right)$ and RuBP carboxylation $\left(V_{\mathrm{cmax}}\right)$ were calculated [49].

\subsection{PSI and PSII Measurements}

We used a Dual-PAM 100 measuring system (Heinz Walz, Effeltrich, German) to measure PSI and PSII parameters under atmospheric $\mathrm{CO}_{2}$ condition. After illumination at $1455 \mu \mathrm{mol}$ photons $\mathrm{m}^{-2} \mathrm{~s}^{-1}$ for $5 \mathrm{~min}$ to activate photosynthetic electron sinks, leaves were exposed to FL alternating between low light (59 $\mu \mathrm{mol}$ photons $\left.\mathrm{m}^{-2} \mathrm{~s}^{-1}, 2 \mathrm{~min}\right)$ and high light $\left(1455 \mu \mathrm{mol}\right.$ photons $\left.\mathrm{m}^{-2} \mathrm{~s}^{-1}, 1 \mathrm{~min}\right)$. PSI parameters were calculated as follows: $\mathrm{Y}(\mathrm{I})=\left(P_{\mathrm{m}}{ }^{\prime}-P\right) / P_{\mathrm{m}} ; \mathrm{Y}(\mathrm{ND})=P / P_{\mathrm{m}} ; \mathrm{Y}(\mathrm{NA})=\left(P_{\mathrm{m}}-P_{\mathrm{m}}{ }^{\prime}\right) / P_{\mathrm{m}}$. $\mathrm{Y}(\mathrm{I})$, the quantum yield of PSI photochemistry; $Y(N D)$, the quantum yield of PSI non-photochemical energy dissipation due to donor side limitation; Y(NA), the quantum yield of PSI nonphotochemical energy dissipation due to acceptor side limitation. PSII parameters were calculated as follows: $\mathrm{Y}(\mathrm{II})=\left(F_{m}{ }^{\prime}-F_{s}\right) / F_{m}{ }^{\prime} ; \mathrm{NPQ}=\left(F_{m}-F_{m}{ }^{\prime}\right) / F_{m}{ }^{\prime} ; \mathrm{Y}(\mathrm{NO})=F_{s} / F_{m} . \mathrm{Y}(\mathrm{II})$, the effective quantum yield of PSII photochemistry; NPQ, non-photochemical quenching in PSII; Y(NO), the quantum yield of non-regulatory energy dissipation in PSII. The relative photosynthetic electron transport rate through PSI and PSII were calculated as: $\mathrm{rETRI}=\mathrm{PPFD} \times \mathrm{Y}(\mathrm{I}) \times 0.84 \times 0.5 ; \mathrm{rETRII}=\mathrm{PPFD} \times \mathrm{Y}(\mathrm{II}) \times 0.84 \times 0.5 . \mathrm{rETRI}$ minus rETRII is assumed to be the rate of $\mathrm{CEF}$.

\subsection{Electrochromic Shift Measurement}

A Dual-PAM 100 equipped with a P515/535 emitter-detector module (Heinz Walz) was used measure the electrochromic shift (ECS) signals. After light adaptation at $1455 \mu \mathrm{mol}$ photons $\mathrm{m}^{-2} \mathrm{~s}^{-1}$ for $5 \mathrm{~min}$, leaves were illuminated at $59 \mu \mathrm{mol}$ photons $\mathrm{m}^{-2} \mathrm{~s}^{-1}$ for $2 \mathrm{~min}$. Afterwards, light intensity was changed to $1455 \mu \mathrm{mol}$ photons $\mathrm{m}^{-2} \mathrm{~s}^{-1}$, and ECS dark interval relaxation kinetics (DIRK $\mathrm{ECS}_{\mathrm{S}}$ ) were recorded after this light transition for $10 \mathrm{~s}$ or $60 \mathrm{~s}$. The proton gradient $(\Delta \mathrm{pH})$ component of proton motive force were calculated using DIRK $K_{E C S}[50,51]$. The chloroplast ATP synthase activity $\left(g_{\mathrm{H}}{ }^{+}\right)$was estimated as the inverse of the decay time constant of the first-order ECS relaxation [52]. 


\subsection{Statistical Analysis}

We determined whether significant differences existed between HL- and ML-plants using $t$-test $(\alpha=0.05)$. The software SigmaPlot 10.0 was used for graphing and fitting.

\section{Results}

Upon the light intensity changing from LL $\left(59 \mu \mathrm{mol}\right.$ photons $\left.\mathrm{m}^{-2} \mathrm{~s}^{-1}\right)$ to HL $(1455 \mu \mathrm{mol}$ photons $\mathrm{m}^{-2} \mathrm{~s}^{-1}$ ), the quantum yield of PSI photochemistry (Y(I)) rapidly decreased in both types of leaves (Figure 1A). Under high-light phases, HL-plants had higher Y(I) values than ML-plants (Figure 1A). At LL, the quantum yield of energy dissipation due to donor-side limitation, Y(ND), was similar in HL- and ML-plants. However, after the transition from LL to HL for $10 \mathrm{~s}, \mathrm{Y}(\mathrm{ND})$ increased more quickly in HL-plants (Figure 1B). Concomitantly, the quantum yield of energy dissipation due to acceptor-side limitation, Y(NA), increased to a much higher level in ML-plants (Figure 1C), indicating that the PSI over-reduction under FL was aggravated in ML-plants. Similar to the performance of $Y(I)$, the effective quantum yield of PSII photochemistry, Y(II), rapidly decreased in both types of leaves by transitioning from LL to HL (Figure 2A). Furthermore, HL-plants displayed higher Y(II) values under high-light phases (Figure 2A). After transition from LL to HL for $10 \mathrm{~s}$, non-photochemical quenching in PSII, NPQ, rapidly increased to approximately $80 \%$ of the maximum level in both HL- and ML-plants (Figure 2B), diminishing the quantum yield of non-regulatory energy dissipation in PSII (Y(NO)) (Figure 2C). Furthermore, ML-plants had higher $\mathrm{Y}(\mathrm{NO})$ than HL-plants, indicating more excess light energy in ML-plants.

By transitioning from LL to HL, the relative PSI electron flow (rETRI) progressively increased in HL-plants (Figure 3A). By comparison, rETRI first increased and then decreased in ML-plants. The relative PSII electron flow (rETRII) progressively increased in both types of leaves, and HL-plants showed much higher rETRI and rETRII values in high-light phases (Figure 3B). In HL-plants, the rETRII values after this light transition for $60 \mathrm{~s}$ were much higher than those for $10 \mathrm{~s}$. By comparison, rETRII just increased slightly in ML-plants. These results indicated that, within the initial $10 \mathrm{~s}$ after this light transition, the $\mathrm{CO}_{2}$ assimilation was strongly restricted in HL-plants. In order to evaluate the performance of CEF under fluctuating light, we analyzed the change in rETRI-rETRII during FL treatment. HLand ML-plants showed similarly low values of rETRI-rETRII under LL. Interestingly, the changing pattern of CEF under FL varied between HL- and ML-plants (Figure 3C). After the transition from LL to HL, rETRI-rETRII rapidly increased to the maximum value in $10 \mathrm{~s}$ and maintained stable over time in HL-plants. By comparison, rETRI-rETRII firstly increased and subsequently rapidly decreased in ML-plants. In the first four cycles of LL/HL, the increase of CEF to the maximum value in ML-plants needed $30 \mathrm{~s}$, indicating the delayed CEF activation in ML-plants. After the abrupt increase in illumination, the rETRI/rETRII ratio first increased and then decreased, suggesting the transient CEF stimulation under FL (Figure S1). Furthermore, the contribution of CEF to total photosynthetic electron flow was enhanced in ML-plants (Figure S1). 

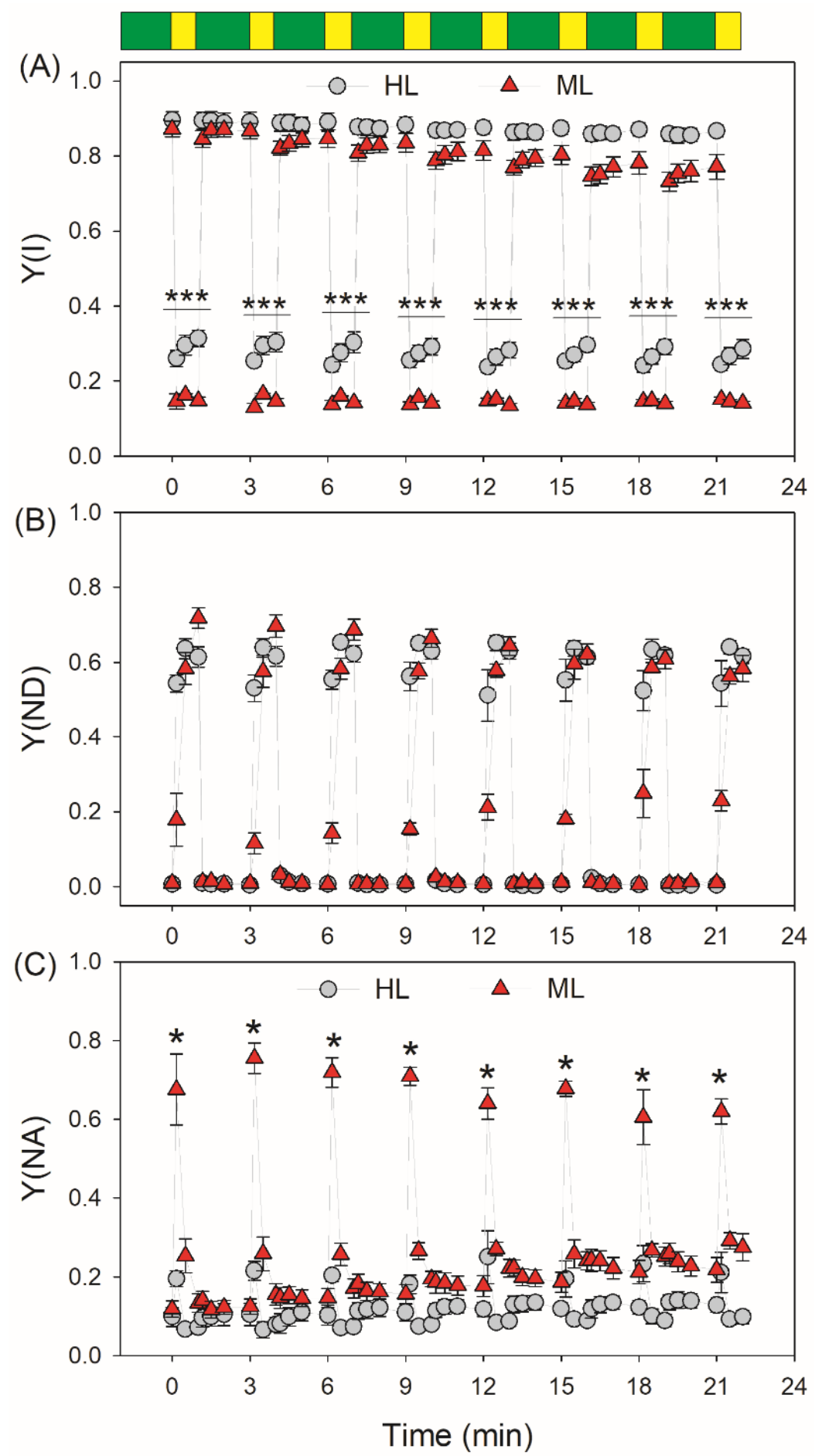

Figure 1. Changes in PSI parameters during fluctuating light in HL- and ML-plants of tomato. (A) Y(I), the quantum yield of PSI photochemistry; (B) Y(ND), the quantum yield of PSI nonphotochemical energy dissipation due to the donor side limitation; (C) Y(NA), the quantum yield of PSI non-photochemical energy dissipation due to the acceptor side limitation. Data are shown as means $\pm S E(n=5)$. Green bars indicate low light $\left(59 \mu \mathrm{mol}\right.$ photons $\left.\mathrm{m}^{-2} \mathrm{~s}^{-1}\right)$; yellow bars indicate high light $\left(1455 \mu \mathrm{mol}\right.$ photons $\left.\mathrm{m}^{-2} \mathrm{~s}^{-1}\right)$. Asterisk indicates a significant difference between HL- and ML-plants. 

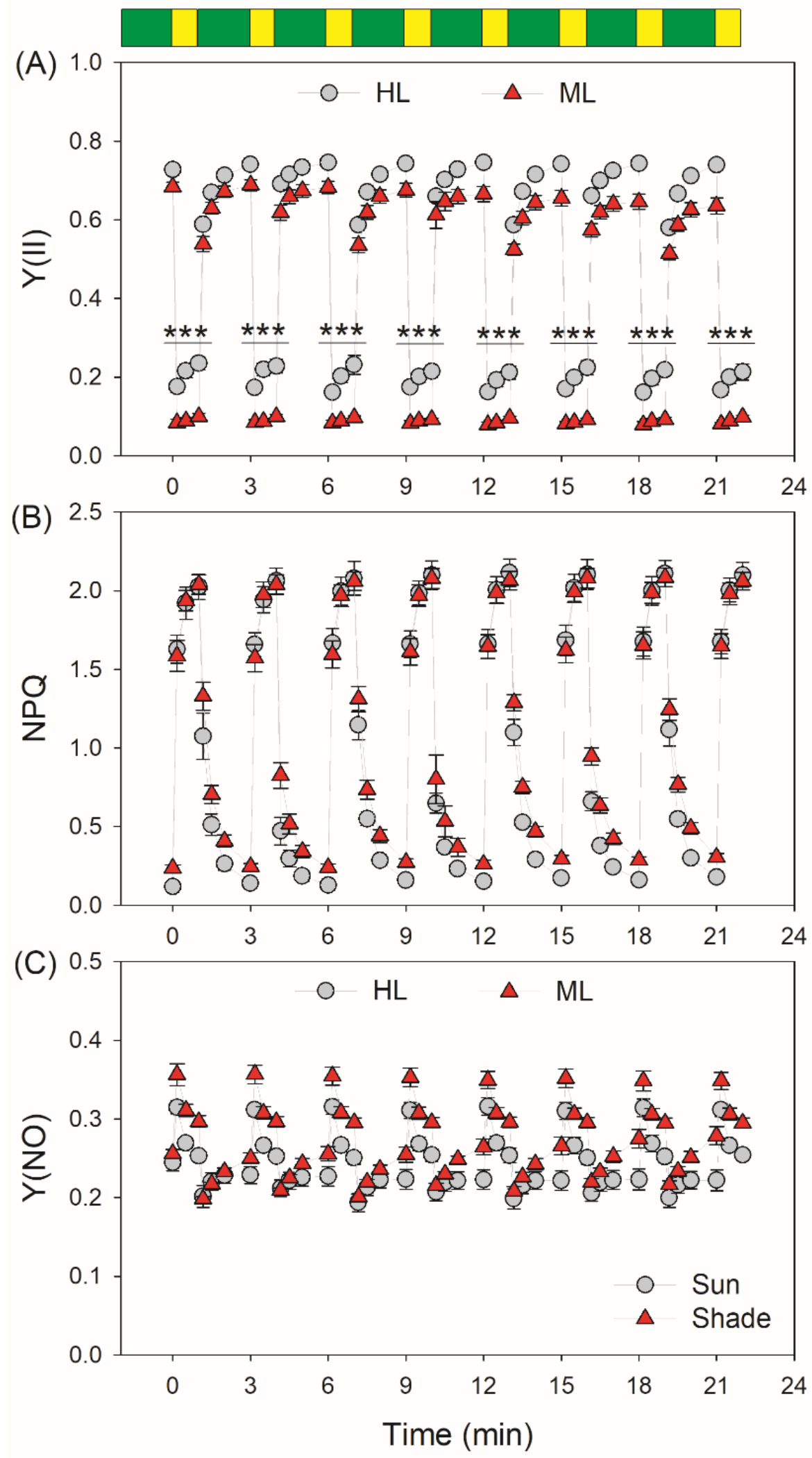

Figure 2. Changes in PSII parameters during fluctuating light in HL- and ML-plants of tomato. (A) Y(II), the effective quantum yield of PSII photochemistry; (B) NPQ, non-photochemical quenching in PSII; (C) Y(NO), the quantum yield of non-regulatory energy dissipation in PSII. Data are shown as means $\pm S E(n=5)$. Green bars indicate low light $\left(59 \mu \mathrm{mol}\right.$ photons $\left.\mathrm{m}^{-2} \mathrm{~s}^{-1}\right)$; yellow bars indicate high light $\left(1455 \mu \mathrm{mol}\right.$ photons $\left.\mathrm{m}^{-2} \mathrm{~s}^{-1}\right)$. Asterisk indicates a significant difference between HL- and ML-plants. 

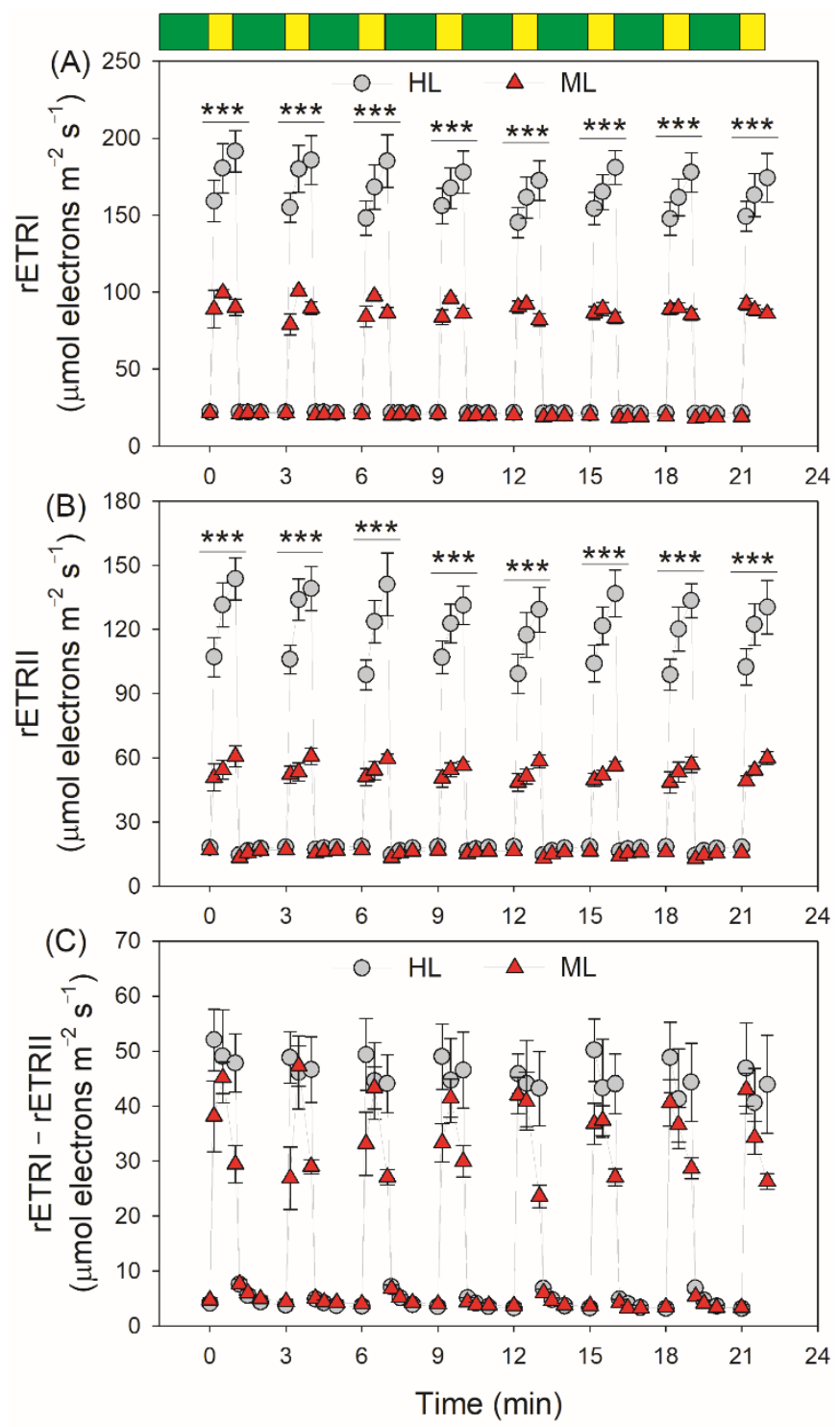

Figure 3. Changes in relative photosynthetic electron transport rates (rETRs) during fluctuating light in HL- and ML-plants of tomato. (A) rETRI, ETR through photosystem PSI; (B) rERTII, ETR through PSII; (C) rETRI-rETRII, estimated rate of cyclic electron flow. Data are shown as means \pm SD $(n=5)$. Green bars indicate low light $\left(59 \mu \mathrm{mol}\right.$ photons $\left.\mathrm{m}^{-2} \mathrm{~s}^{-1}\right)$; yellow bars indicate high light $(1455 \mu \mathrm{mol}$ photons $\mathrm{m}^{-2} \mathrm{~s}^{-1}$ ). Asterisk indicates a significant difference between HL- and ML-plants.

Because $\triangle \mathrm{pH}$ significantly regulates PSI redox state and NPQ induction under high light $[53,54]$, we next examined the change in $\Delta \mathrm{pH}$ under fluctuating light. After transition from LL to HL for $10 \mathrm{~s}$, the $\Delta \mathrm{pH}$ value was slightly lower than that for $60 \mathrm{~s}$ in HL-plants (Figure $4 \mathrm{~A}$ ), suggesting that the $\Delta \mathrm{pH}$ formation within the first $10 \mathrm{~s}$ was almost sufficient for photosynthetic regulation in HL-plants. By comparison, the $\Delta \mathrm{pH}$ value for $10 \mathrm{~s}$ was significantly lower than that for $60 \mathrm{~s}$ in ML-plants (Figure 4A), indicating that the $\Delta \mathrm{pH}$ formation within the first $10 \mathrm{~s}$ was insufficient to regulate photosynthetic apparatus in ML-plants. After this light transition, the chloroplast ATP synthase activity $\left(g_{\mathrm{H}}{ }^{+}\right)$gradually increased in HL-plants but was maintained stable in ML-plants (Figure 4B). Because a decrease in $\mathrm{g}_{\mathrm{H}}{ }^{+}$can enhance the formation of $\Delta \mathrm{pH}$, the flexibility of $g_{\mathrm{H}}{ }^{+}$upon a sudden transition from LL to HL in HL-plants likely favored the rapid generation of $\Delta \mathrm{pH}$. 

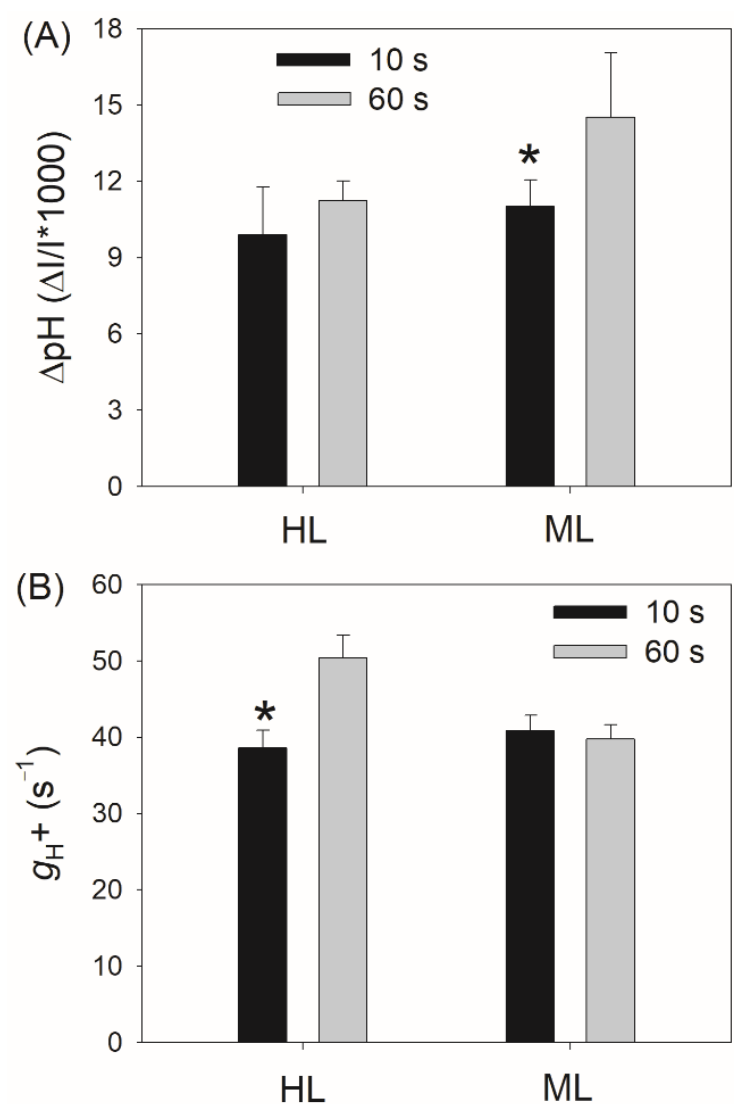

Figure 4. Changes in proton gradient $(\Delta \mathrm{pH})(\mathbf{A})$ and chloroplast ATP synthase activity $\left(g_{\mathrm{H}^{+}}{ }^{+}\right)(\mathbf{B})$ during fluctuating light in HL- and ML-plants of tomato. $\Delta \mathrm{pH}$ and $g_{\mathrm{H}}{ }^{+}$were measured after transition from 59 to $1455 \mu \mathrm{mol}$ photons $\mathrm{m}^{-2} \mathrm{~s}^{-1}$ for $10 \mathrm{~s}$ and $60 \mathrm{~s}$. Data are shown as means $\pm \mathrm{SE}(\mathrm{n}=5)$. Asterisk indicates a significant difference between $10 \mathrm{~s}$ and $60 \mathrm{~s}$.

After fluctuating light treatment for eight cycles of low/high light, ML-plants showed a larger decrease in Pm than HL-plants (Figure 5A). Thus, FL induced a stronger PSI photoinhibition in ML-plants. Furthermore, we found a tight positive relationship between PSI photoinhibition and Y(NA) after transition from LL to HL for $10 \mathrm{~s}$ (Y(NA) $10 \mathrm{~s}$ ) (Figure 5B). Therefore, the greater PSI photoinhibition in ML-plants induced by FL was mainly caused by the transient PSI over-reduction.

The PSI redox state under FL is significantly affected by the electron sink downstream of PSI $[38,55,56]$. Compared with ML-plants, HL-plants not only displayed higher capacities for the maximum rates of RuBP carboxylation $\left(V_{\mathrm{cmax}}\right)$ and regeneration $\left(J_{\max }\right)$, and photosynthetic $\mathrm{CO}_{2}$ assimilation rate $\left(A_{\text {sat }}\right)$, but also showed higher electron flow for photorespiration $\left(J_{\mathrm{O}}\right)$ when $\mathrm{CO}_{2}$ assimilation was restricted at low $\mathrm{CO}_{2}$ concentrations (Figure 6). Therefore, the electron sink downstream of PSI was significantly enhanced in HL-plants. Within the first $60 \mathrm{~s}$ after transition from 50 to $1500 \mu \mathrm{mol}$ photons $\mathrm{m}^{-2} \mathrm{~s}^{-1}$, the gross $\mathrm{CO}_{2}$ assimilation rate did not differ between HL- and ML-plants (Figure 6), indicating that the variation of $Y(N A)_{10 \text { s }}$ between HL- and ML-plants was caused by photorespiration rather than the Calvin-Benson cycle. Furthermore, we found the maximum $J_{\mathrm{O}}$ was negatively correlated to the PSI over-reduction under FL and FL-induced PSI photoinhibition (Figure 7), indicating that the enhancement of photorespiration in HL-plants alleviated the PSI over-reduction under FL and thus mitigated PSI photoinhibition. 

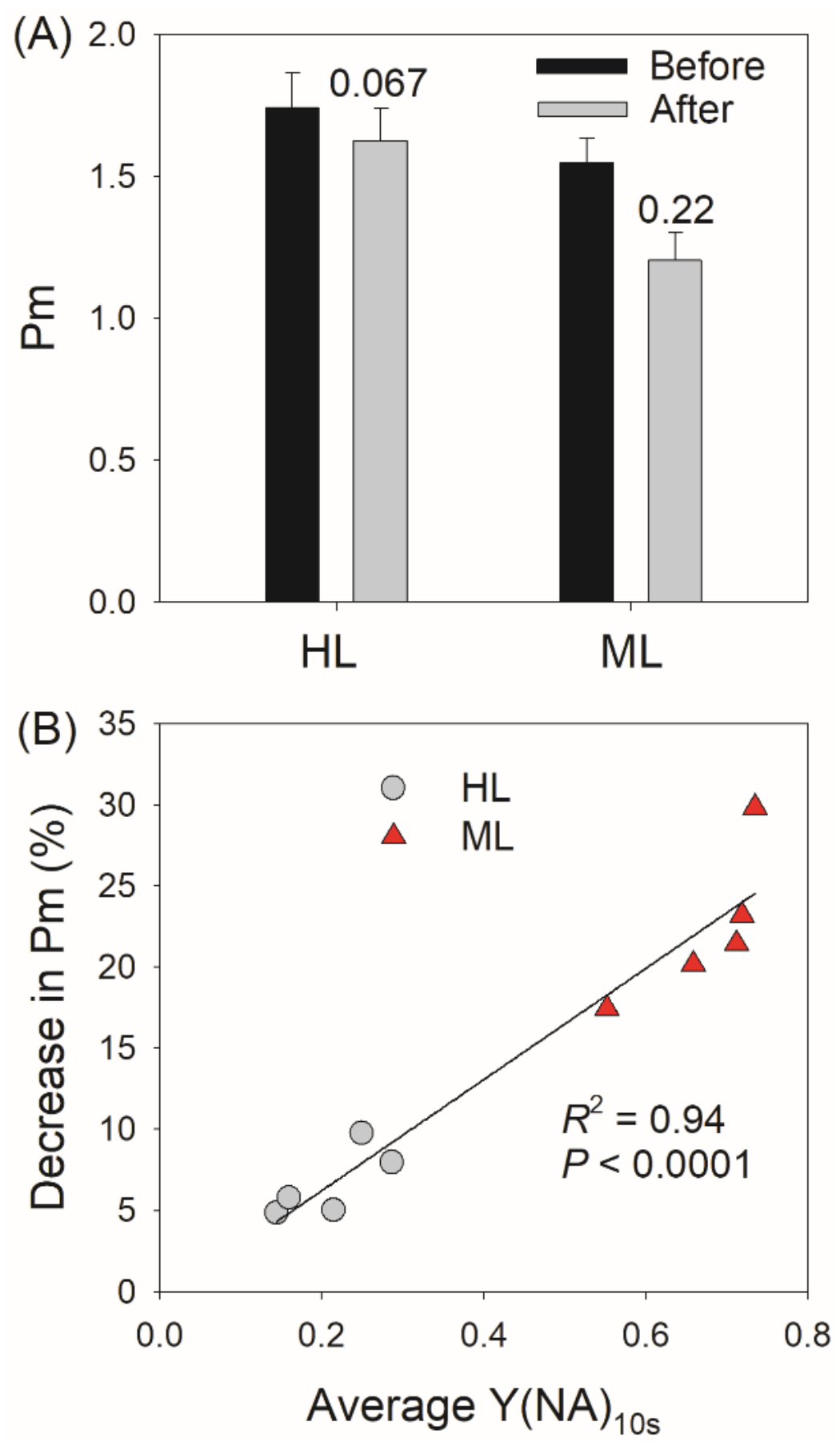

Figure 5. (A) The decrease in Pm after fluctuating light treatment for $24 \mathrm{~min}$ in HL- and ML-plants of tomato, and the decreasing amplitude was displayed in it. (B) Relationships between the decrease in Pm and the average Y(NA) after transition from 59 to $1455 \mu \mathrm{mol}$ photons $\mathrm{m}^{-2} \mathrm{~s}^{-1}$ for $10 \mathrm{~s}$ during fluctuating light treatment in HL- and ML-plants. Data are shown as means \pm SE $(n=5)$. Asterisk indicates a significant difference between HL- and ML-plants. Each symbol represents an individual leaf. 

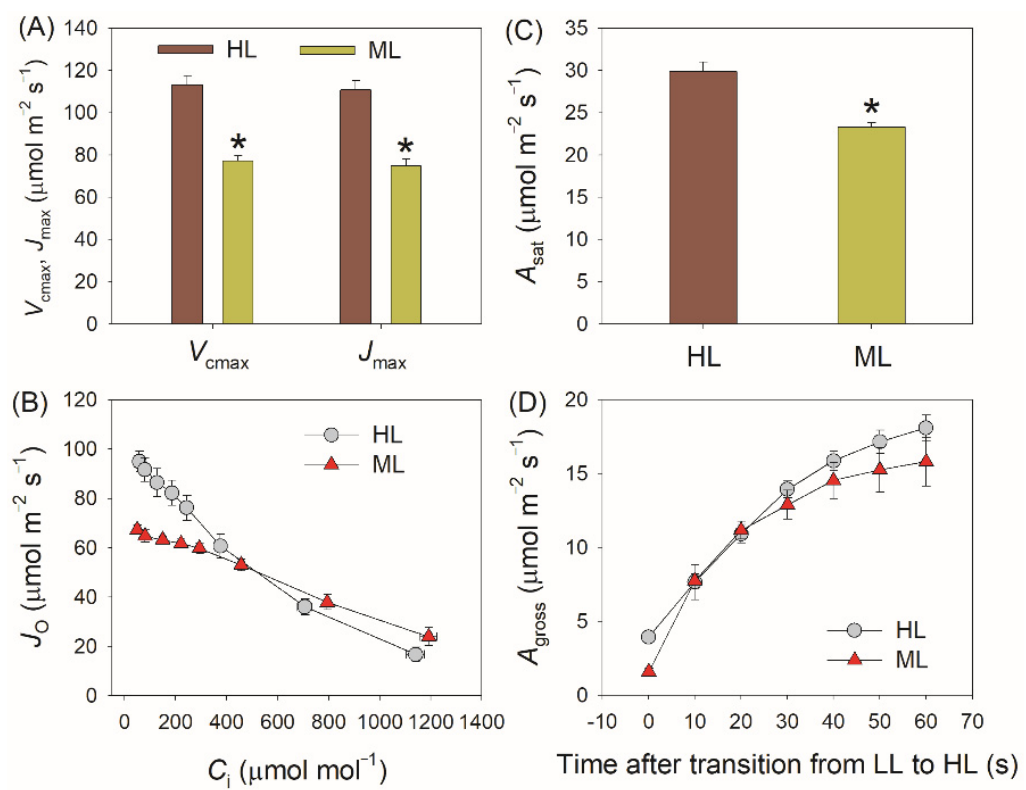

Figure 6. (A) The maximum rates of RuBP carboxylation $\left(V_{\mathrm{cmax}}\right)$ and regeneration $\left(J_{\max }\right),(\mathbf{B})$ response of electron flow to photorespiration $\left(J_{\mathrm{O}}\right)$ to incident intercellular $\mathrm{CO}_{2}$ concentration $\left(C_{\mathrm{i}}\right)$, (C) the saturating net $\mathrm{CO}_{2}$ assimilation rate $\left(A_{\mathrm{sat}}\right)$ at $1500 \mu \mathrm{mol}$ photons $\mathrm{m}^{-2} \mathrm{~s}^{-1}$ and $400 \mu \mathrm{mol}$ $\mathrm{CO}_{2} \mathrm{~mol}^{-1}$, and (D) change in gross $\mathrm{CO}_{2}$ assimilation rate $\left(A_{\text {gross }}\right)$ after transition from 50 to $1500 \mu \mathrm{mol}$ photons $\mathrm{m}^{-2} \mathrm{~s}^{-1}$ in HL- and ML-plants. Data are shown as means $\pm \mathrm{SD}(\mathrm{n}=5)$. Asterisk indicates a significant difference between HL- and ML-plants.
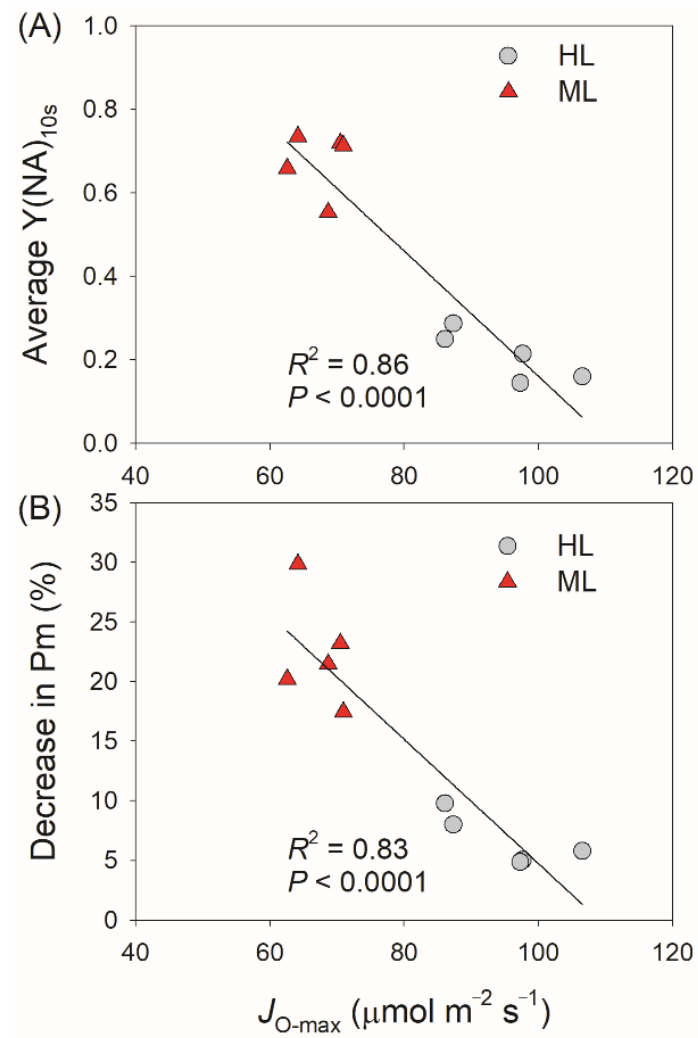

Figure 7. Effects of the maximum electron flow to photorespiration (JO-max) on the average Y(NA) after transition from 59 to $1455 \mu \mathrm{mol}$ photons $\mathrm{m}^{-2} \mathrm{~s}^{-1}$ for $10 \mathrm{~s}(\mathbf{A})$ and the decrease in Pm (B) during fluctuating light treatment in HL- and ML-plants. JO-max was obtained from the $\mathrm{CO}_{2}$ response curves in Figure 6. 


\section{Discussion}

After an abrupt increase in illumination, the slow kinetics of $\mathrm{CO}_{2}$ assimilation led to the lack of $\mathrm{NADP}^{+}$and made PSI to be over-reduced owing to the restriction of electron flow from PSI to NADP ${ }^{+}$. Some previous studies reported that FL induced a marked PSI photoinhibition in some angiosperms [20,21,57,58]. Furthermore, in Arabidopsis thaliana (Arabidopsis) and Erigeron annuus, FL-induced PSI photoinhibition was stronger in LLplants than in HL-plants [59]. Therefore, growth light can significantly affect the response of PSI to FL. However, the underlying mechanisms are not clear. Here we demonstrated that, upon transition from LL to HL, tomato ML-plants significantly showed a stronger PSI over-reduction than HL-plants, ultimately causing higher PSI photoinhibition in ML-plants. Therefore, ML-plants can fine-turn the redox state of PSI under FL to a much lesser extent. Plants grown under high light might display slight damage of PSI FeS cluster after exposure to high light [60]. In this study, we measured all photosynthetic parameters in the morning (a.m. 9:00-12:00), which might exclude the possibility of PSI photodamage in HL-plants.

The PSI redox state under FL is largely affected by donor and acceptor side regulation [21]. During donor side regulation, a high $\Delta \mathrm{pH}$ can down-regulates the plastoquinone (PQ) oxidation at the Cyt $b_{6} / f$ complex, which restricts the electron transport from PQ to plastocyanin (PC) and, thus, avoids excess electron flow to PSI [61]. If $\Delta \mathrm{pH}$ formation under high light was impaired, PSI would be over-reduced, leading to uncontrolled PSI photoinhibition [62,63]. Therefore, a sufficient $\Delta \mathrm{pH}$ is indispensable to PSI photoprotection under high light. The $\Delta \mathrm{pH}$ formation under high light is mainly affected by photosynthetic electron flow and chloroplast ATP synthase activity $[53,64]$. After transition from LL to HL, HL-plants displayed high levels of photosynthetic electron transport rates and a relatively low chloroplast ATP synthase activity, contributing to the sufficient $\Delta \mathrm{pH}$ formation. By comparison, the ML-plants generated an insufficient $\Delta \mathrm{pH}$ after this light transition for $10 \mathrm{~s}$. Therefore, HL-plants reinforced the PSI donor side regulation under FL.

In PSI acceptor side regulation, reducing power in PSI is consumed by linear electron flow, photo-reduction of $\mathrm{O}_{2}$ mediated by the Mehler reactions and Flvs $[33,65,66]$. Flvdependent alternative electron flow was lost in angiosperms during evolution [37]. The $\mathrm{O}_{2}$ photo-reduction mediated by the Mehler reactions, called water-water cycle, could rapidly consume excess electrons in PSI and thus avoided PSI over-reduction under FL $[56,67,68]$. In the present study, a transient PSI over-reduction under FL indicated that water-water cycle was not significant in tomato leaves. The excess PSII electron flow is the prerequisite for PSI over-reduction $[36,63,69,70]$. Although HL-plants displayed much higher PSII electron flow than ML-plants, HL-plants showed a rapid oxidation of PSI upon the sudden transition from LL to HL. These results suggested that HL-plants have the ability to rapidly consume the large amounts of reducing power in PSI through acceptor side regulation.

After transition from LL to HL for $10 \mathrm{~s}$, the value of rETRII was much higher in HL-plants than ML-plants (Figure 3B), whereas the gross $\mathrm{CO}_{2}$ assimilation rate showed no significant difference between them (Figure 6). These results indicated that, upon a sudden increase in illumination, the difference in rETRII between HL- and ML-plants was not attributed to the Calvin-Benson cycle but was caused by the change in photorespiration. Accordingly, within the first $10 \mathrm{~s}$ after this light transition, electron flow for photorespiration was the major component of PSII electron flow in HL-plants. Furthermore, photorespiration could rapidly consume the excess reducing power in PSI [42]. An increase in photorespiratory pathway can accelerate the consumption of NADPH and subsequently elevates the $\mathrm{NADP}^{+} / \mathrm{NADPH}$ ratio. Therefore, the enhanced photorespiratory pathway in HL-plants facilitates the outflow of electrons from PSI to $\mathrm{NADP}^{+}$under FL and eventually alleviates PSI over-reduction at acceptor side. Furthermore, the higher electron flow to photorespiration in HL-plants helped the rapid formation of $\Delta \mathrm{pH}$ after transition from low to high light, which alleviated PSI over-reduction under FL at donor side. Taking together, the enhancement of photorespiration in HL-plants protected PSI against photoinhibition under FL at donor and acceptor sides. 
The photorespiratory pathway starts with the oxygenation of RuBP, which leads to the formation of 3-phosphoglycerate (3-PGA) and 2-phosphoglycolate (2-PG) [71]. 2PG is a dead-end intermediate of photosynthesis, which cannot directly be used and strongly impairs plant carbon metabolism [72-74]. To prevent the accumulation of 2-PG, photorespiratory pathway converts 2-PG into 3-PGA to replenish the Calvin-Benson cycle [75,76]. Therefore, acceleration of the photorespiratory pathway can significantly boost $\mathrm{CO}_{2}$ assimilation rate and plant growth via optimized RuBP regeneration and preventing 2-PG mediated down-regulation of the Calvin-Benson cycle [43,77-79]. Thus, the enhancement of photorespiratory pathway has the potential to improve plant growth and crop yield under field FL conditions. Under FL conditions, avoiding PSI photoinhibition is a premise of the maintenance of $\mathrm{CO}_{2}$ assimilation rate [31,80]. This is in good agreement with the presented results and the hypothesis that that the photorespiratory pathway acted as a safety valve to protect PSI under FL.

In previous studies on PSI photoprotection under FL, CEF is thought to be the main factor affecting the PSI redox state. During CEF, electrons are transferred from ferredoxin to PSI, which is accompanied with the proton translocation [81-83]. The CEF-dependent formation of $\Delta \mathrm{pH}$ is critical for NPQ induction and PSII photoprotection under high light [84]. Moreover, once CEF activity was decreased by mutation of PGR5- and/or NDHpathway, the PSI over-reduction under high light would be aggravated, leading to severe PSI photoinhibition $[62,63,80,85]$. After transition from LL to HL, CEF first increased and then rapidly decreased in ML-plants, which was consistent with previous results reported in Arabidopsis and tobacco plants grown under low light [20,22]. The first transient CEF stimulation helped the formation of $\triangle \mathrm{pH}$. The latter decrease in CEF prevented an overacidification of thylakoid lumen, which maximized the photosynthetic light use efficiency. However, we found that the CEF performance in HL-plants was different from ML-plants. After the same light transition, the rate of CEF rapidly increased and then was maintained stable in HL-plants. Furthermore, within the first $30 \mathrm{~s}$ after transition from LL to HL, ML-plants displayed higher rETRI/rETRII ratios than HL-plants (Figure S1). These results indicated that ML-plants showed a larger contribution of CEF to total photosynthetic electron transport under FL. Therefore, to prevent uncontrolled over-reduction of PSI under FL, ML-plants enhanced the stimulation of CEF to compensate for the shortage of photorespiration.

\section{Conclusions}

We here showed that ML-plants displayed a greater PSI over-reduction under FL than HL-plants in tomato. As a result, FL induced a stronger PSI photoinhibition in MLplants. Furthermore, the up-regulation of photorespiration in HL-plants enhanced the outflow of electrons from PSI under FL and thus alleviated PSI photoinhibition. Therefore, photorespiration acts as an important valve for PSI protection under FL. In ML-plants, CEF was highly activated to compensate for the lower capacity of photorespiration, which prevented uncontrolled PSI photoinhibition. Taking together, HL- and ML-plants likely use different strategies to protect their photosynthetic apparatus under FL. Future studies involving defined photorespiration mutants are needed to shed more light on these aspects.

Supplementary Materials: The following supporting information can be downloaded at: https: / / www.mdpi.com/article/10.3390/plants11020195/s1, Figure S1: Changes in the rETR/rETRII ratio during fluctuating light in HL- and ML-plants of tomato. Green bars indicate low light (59 $\mu \mathrm{mol}$ photons $\left.\mathrm{m}^{-2} \mathrm{~s}^{-1}\right)$; yellow bars indicate high light $\left(1455 \mu \mathrm{mol}\right.$ photons $\left.\mathrm{m}^{-2} \mathrm{~s}^{-1}\right)$. Data are shown as means $\pm S E(n=5)$.

Author Contributions: Conceptualization, W.H. and S.Z.; methodology, W.H.; validation, Q.S., H.S. and W.H.; formal analysis, W.H.; investigation, Q.S., H.S.; resources, H.S.; writing-original draft preparation, W.H.; writing-review and editing, S.T. and S.Z.; funding acquisition, W.H. and S.Z. All authors have read and agreed to the published version of the manuscript. 
Funding: This work was supported by the National Natural Science Foundation of China (Grant 31971412), and the Project for Innovation Team of Yunnan Province (202105AE160012).

Institutional Review Board Statement: Not applicable.

Informed Consent Statement: Not applicable.

Data Availability Statement: The data presented in this study are available on request from the corresponding author.

Conflicts of Interest: The authors declare no conflict of interest.

\section{References}

1. Miyake, C.; Horiguchi, S.; Makino, A.; Shinzaki, Y.; Yamamoto, H.; Tomizawa, K.I. Effects of light intensity on cyclic electron flow around PSI and its relationship to non-photochemical quenching of Chl fluorescence in tobacco leaves. Plant Cell Physiol. 2005, 46, 1819-1830. [CrossRef]

2. Zivcak, M.; Brestic, M.; Kalaji, H.M.; Govindjee, N. Photosynthetic responses of sun- and shade-grown barley leaves to high light: Is the lower PSII connectivity in shade leaves associated with protection against excess of light? Photosynth. Res. 2014, 119, 339-354. [CrossRef]

3. Tan, S.-L.; Liu, T.; Zhang, S.-B.; Huang, W. Balancing light use efficiency and photoprotection in tobacco leaves grown at different light regimes. Environ. Exp. Bot. 2020, 175, 104046. [CrossRef]

4. $\quad$ Oguchi, R.; Hikosaka, K.; Hirose, T. Does the photosynthetic light-acclimation need change in leaf anatomy? Plant Cell Environ. 2003, 26, 505-512. [CrossRef]

5. Ferroni, L.; Brestič, M.; Živčak, M.; Cantelli, R.; Pancaldi, S. Increased photosynthesis from a deep-shade to high-light regime occurs by enhanced $\mathrm{CO}_{2}$ diffusion into the leaf of Selaginella martensii. Plant Physiol. Biochem. 2021, 160, 143-154. [CrossRef] [PubMed]

6. Yamori, W.; Evans, J.R.; Von Caemmerer, S. Effects of growth and measurement light intensities on temperature dependence of $\mathrm{CO}_{2}$ assimilation rate in tobacco leaves. Plant Cell Environ. 2010, 33, 332-343. [CrossRef]

7. Ferroni, L.; Suorsa, M.; Aro, E.M.; Baldisserotto, C.; Pancaldi, S. Light acclimation in the lycophyte Selaginella martensii depends on changes in the amount of photosystems and on the flexibility of the light-harvesting complex II antenna association with both photosystems. New Phytol. 2016, 211, 554-568. [CrossRef]

8. Huang, W.; Zhang, S.-B.; Hu, H. Sun leaves up-regulate the photorespiratory pathway to maintain a high rate of $\mathrm{CO}_{2}$ assimilation in tobacco. Front. Plant Sci. 2014, 5, 688. [CrossRef] [PubMed]

9. Takahashi, S.; Bauwe, H.; Badger, M. Impairment of the photorespiratory pathway accelerates photoinhibition of photosystem II by suppression of repair but not acceleration of damage processes in Arabidopsis. Plant Physiol. 2007, 144, 487-494. [CrossRef] [PubMed]

10. Takahashi, S.; Badger, M.R. Photoprotection in plants: A new light on photosystem II damage. Trends Plant Sci. 2011, 16, 53-60. [CrossRef] [PubMed]

11. Slattery, R.A.; Walker, B.J.; Weber, A.P.M.; Ort, D.R. The impacts of fluctuating light on crop performance. Plant Physiol. 2018, 176, 990-1003. [CrossRef]

12. Ferroni, L.; Živčak, M.; Sytar, O.; Kovár, M.; Watanabe, N.; Pancaldi, S.; Baldisserotto, C.; Brestič, M. Chlorophyll-depleted wheat mutants are disturbed in photosynthetic electron flow regulation but can retain an acclimation ability to a fluctuating light regime. Environ. Exp. Bot. 2020, 178, 104156. [CrossRef]

13. Yang, Y.-J.; Ding, X.-X.; Huang, W. Stimulation of cyclic electron flow around photosystem I upon a sudden transition from low to high light in two angiosperms Arabidopsis thaliana and Bletilla striata. Plant Sci. 2019, 287, 110166. [CrossRef]

14. Yang, Y.-J.; Zhang, S.-B.; Huang, W. Photosynthetic regulation under fluctuating light in young and mature leaves of the CAM plant Bryophyllum pinnatum. Biochim. Biophys. Acta-Bioenerg. 2019, 1860, 469-477. [CrossRef]

15. Kimura, H.; Hashimoto-Sugimoto, M.; Iba, K.; Terashima, I.; Yamori, W. Improved stomatal opening enhances photosynthetic rate and biomass production in fluctuating light. J. Exp. Bot. 2020, 71, 2339-2350. [CrossRef] [PubMed]

16. Lawson, T.; Blatt, M.R. Stomatal Size, Speed, and Responsiveness Impact on Photosynthesis and Water Use Efficiency. Plant Physiol. 2014, 164, 1556-1570. [CrossRef] [PubMed]

17. Vialet-Chabrand, S.; Matthews, J.S.A.; Simkin, A.J.; Raines, C.A.; Lawson, T. Importance of Fluctuations in Light on Plant Photosynthetic Acclimation. Plant Physiol. 2017, 173, 2163-2179. [CrossRef] [PubMed]

18. Takagi, D.; Takumi, S.; Hashiguchi, M.; Sejima, T.; Miyake, C. Superoxide and singlet oxygen produced within the thylakoid membranes both cause photosystem I photoinhibition. Plant Physiol. 2016, 171, 1626-1634. [CrossRef] [PubMed]

19. Suorsa, M.; Jarvi, S.; Grieco, M.; Nurmi, M.; Pietrzykowska, M.; Rantala, M.; Kangasjarvi, S.; Paakkarinen, V.; Tikkanen, M.; Jansson, S.; et al. PROTON GRADIENT REGULATION5 is essential for proper acclimation of Arabidopsis photosystem I to naturally and artificially fluctuating light conditions. Plant Cell. 2012, 24, 2934-2948. [CrossRef] [PubMed]

20. Kono, M.; Noguchi, K.; Terashima, I. Roles of the cyclic electron flow around PSI (CEF-PSI) and $\mathrm{O}_{2}$-dependent alternative pathways in regulation of the photosynthetic electron flow in short-term fluctuating light in Arabidopsis thaliana. Plant Cell Physiol. 2014, 55, 990-1004. [CrossRef] [PubMed] 
21. Yamamoto, H.; Shikanai, T. PGR5-dependent cyclic electron flow protects photosystem I under fluctuating light at donor and acceptor sides. Plant Physiol. 2019, 179, 588-600. [CrossRef]

22. Tan, S.-L.; Yang, Y.-J.; Liu, T.; Zhang, S.-B.; Huang, W. Responses of photosystem I compared with photosystem II to combination of heat stress and fluctuating light in tobacco leaves. Plant Sci. 2020, 292, 110371. [CrossRef]

23. Tan, S.-L.; Yang, Y.-J.; Huang, W. Moderate heat stress accelerates photoinhibition of photosystem I under fluctuating light in tobacco young leaves. Photosynth. Res. 2020, 144, 373-382. [CrossRef] [PubMed]

24. Huang, W.; Yang, Y.-J.; Zhang, S.-B. Photoinhibition of photosystem I under fluctuating light is linked to the insufficient $\Delta \mathrm{pH}$ upon a sudden transition from low to high light. Environ. Exp. Bot. 2019, 160, 112-119. [CrossRef]

25. Zivcak, M.; Brestic, M.; Kunderlikova, K.; Sytar, O.; Allakhverdiev, S.I. Repetitive light pulse-induced photoinhibition of photosystem I severely affects $\mathrm{CO}_{2}$ assimilation and photoprotection in wheat leaves. Photosynth. Res. 2015, 126, 449-463. [CrossRef] [PubMed]

26. Brestic, M.; Zivcak, M.; Kunderlikova, K.; Allakhverdiev, S.I. High temperature specifically affects the photoprotective responses of chlorophyll b-deficient wheat mutant lines. Photosynth. Res. 2016, 130, 251-266. [CrossRef] [PubMed]

27. Zivcak, M.; Brestic, M.; Botyanszka, L.; Chen, Y.E.; Allakhverdiev, S.I. Phenotyping of isogenic chlorophyll-less bread and durum wheat mutant lines in relation to photoprotection and photosynthetic capacity. Photosynth. Res. 2019, 139, 239-251. [CrossRef] [PubMed]

28. Dąbrowski, P.; Kalaji, M.H.; Baczewska, A.H.; Pawluśkiewicz, B.; Mastalerczuk, G.; Borawska-Jarmułowicz, B.; Paunov, M.; Goltsev, V. Delayed chlorophyll a fluorescence, MR 820, and gas exchange changes in perennial ryegrass under salt stress. $J$. Lumin. 2017, 183, 322-333. [CrossRef]

29. Allahverdiyeva, Y.; Suorsa, M.; Tikkanen, M.; Aro, E.M. Photoprotection of photosystems in fluctuating light intensities. J. Exp. Bot. 2015, 66, 2427-2436. [CrossRef]

30. Jokel, M.; Johnson, X.; Peltier, G.; Aro, E.M.; Allahverdiyeva, Y. Hunting the main player enabling Chlamydomonas reinhardtii growth under fluctuating light. Plant J. 2018, 94, 822-835. [CrossRef]

31. Storti, M.; Alboresi, A.; Gerotto, C.; Aro, E.; Finazzi, G.; Morosinotto, T. Role of cyclic and pseudo-cyclic electron transport in response to dynamic light changes in Physcomitrella patens. Plant Cell Environ. 2019, 42, 1590-1602. [CrossRef] [PubMed]

32. Storti, M.; Segalla, A.; Mellon, M.; Alboresi, A.; Morosinotto, T. Regulation of electron transport is essential for photosystem I stability and plant growth. New Phytol. 2020, 228, 1316-1326. [CrossRef] [PubMed]

33. Gerotto, C.; Alboresi, A.; Meneghesso, A.; Jokel, M.; Suorsa, M.; Aro, E.-M.; Morosinotto, T. Flavodiiron proteins act as safety valve for electrons in Physcomitrella patens. Proc. Natl. Acad. Sci. USA 2016, 113, 12322-12327. [CrossRef] [PubMed]

34. Alboresi, A.; Storti, M.; Morosinotto, T. Balancing protection and efficiency in the regulation of photosynthetic electron transport across plant evolution. New Phytol. 2019, 221, 105-109. [CrossRef] [PubMed]

35. Shimakawa, G.; Ishizaki, K.; Tsukamoto, S.; Tanaka, M.; Sejima, T.; Miyake, C. The liverwort, Marchantia, drives alternative electron flow using a flavodiiron protein to protect PSI. Plant Physiol. 2017, 173, 1636-1647. [CrossRef] [PubMed]

36. Suorsa, M.; Rossi, F.; Tadini, L.; Labs, M.; Colombo, M.; Jahns, P.; Kater, M.M.; Leister, D.; Finazzi, G.; Aro, E.-M.; et al. PGR5PGRL1-dependent cyclic electron transport modulates linear electron transport rate in Arabidopsis thaliana. Mol. Plant 2016, 9 , 271-288. [CrossRef]

37. Ilík, P.; Pavlovič, A.; Kouřil, R.; Alboresi, A.; Morosinotto, T.; Allahverdiyeva, Y.; Aro, E.M.; Yamamoto, H.; Shikanai, T. Alternative electron transport mediated by flavodiiron proteins is operational in organisms from cyanobacteria up to gymnosperms. New Phytol. 2017, 214, 967-972. [CrossRef]

38. Yamamoto, H.; Takahashi, S.; Badger, M.R.; Shikanai, T. Artificial remodelling of alternative electron flow by flavodiiron proteins in Arabidopsis. Nat. Plants 2016, 2, 16012. [CrossRef] [PubMed]

39. Shikanai, T.; Yamamoto, H. Contribution of cyclic and pseudo-cyclic electron transport to the formation of proton motive force in chloroplasts. Mol. Plant 2017, 10, 20-29. [CrossRef] [PubMed]

40. Walker, B.J.; Strand, D.D.; Kramer, D.M.; Cousins, A.B. The response of cyclic electron flow around photosystem I to changes in photorespiration and nitrate assimilation. Plant Physiol. 2014, 165, 453-462. [CrossRef] [PubMed]

41. Sakoda, K.; Yamori, W.; Shimada, T.; Sugano, S.S.; Hara-Nishimura, I.; Tanaka, Y. Higher stomatal density improves photosynthetic induction and biomass production in Arabidopsis under fluctuating light. Front. Plant Sci. 2020, 11, 1308. [CrossRef]

42. Huang, W.; Hu, H.; Zhang, S.-B. Photorespiration plays an important role in the regulation of photosynthetic electron flow under fluctuating light in tobacco plants grown under full sunlight. Front. Plant Sci. 2015, 6, 621. [CrossRef] [PubMed]

43. Timm, S.; Florian, A.; Arrivault, S.; Stitt, M.; Fernie, A.R.; Bauwe, H. Glycine decarboxylase controls photosynthesis and plant growth. FEBS Lett. 2012, 586, 3692-3697. [CrossRef]

44. Wada, S.; Suzuki, Y.; Takagi, D.; Miyake, C.; Makino, A. Effects of genetic manipulation of the activity of photorespiration on the redox state of photosystem I and its robustness against excess light stress under $\mathrm{CO}_{2}$-limited conditions in rice. Photosynth. Res. 2018, 137, 431-441. [CrossRef]

45. Shimakawa, G.; Miyake, C. Oxidation of P700 Ensures Robust Photosynthesis. Front. Plant Sci. 2018, 9, 1617. [CrossRef]

46. Genty, B.; Briantais, J.-M.; Baker, N.R. The relationship between the quantum yield of photosynthetic electron transport and quenching of chlorophyll fluorescence. Biochim. Biophys. Acta-Gen. Subj. 1989, 990, 87-92. [CrossRef]

47. Krall, J.P.; Edwards, G.E. Relationship between photosystem II activity and $\mathrm{CO}_{2}$ fixation in leaves. Physiol. Plant 1992, 86, 180-187. [CrossRef] 
48. Valentini, R.; Epron, D.; De Angelis, P.; Matteucci, G.; Dreyer, E. In situ estimation of net $\mathrm{CO}_{2}$ assimilation, photosynthetic electron flow and photorespiration in Turkey oak (Q. cerris L.) leaves: Diurnal cycles under different levels of water supply. Plant Cell Environ. 1995, 18, 631-640. [CrossRef]

49. Long, S.P.; Bernacchi, C.J. Gas exchange measurements, what can they tell us about the underlying limitations to photosynthesis? Procedures and sources of error. J. Exp. Bot. 2003, 54, 2393-2401. [CrossRef] [PubMed]

50. Sacksteder, C.A.; Jacoby, M.E.; Kramer, D.M. A portable, non-focusing optics spectrophotometer (NoFOSpec) for measurements of steady-state absorbance changes in intact plants. Photosynth. Res. 2001, 70, 231-240. [CrossRef] [PubMed]

51. Takizawa, K.; Kanazawa, A.; Kramer, D.M. Depletion of stromal Pi induces high "energy-dependent" antenna exciton quenching (qE) by decreasing proton conductivity at CFO-CF1 ATP synthase. Plant Cell Environ. 2008, 31, 235-243. [CrossRef] [PubMed]

52. Baker, N.R.; Harbinson, J.; Kramer, D.M. Determining the limitations and regulation of photosynthetic energy transduction in leaves. Plant Cell Environ. 2007, 30, 1107-1125. [CrossRef] [PubMed]

53. Takagi, D.; Amako, K.; Hashiguchi, M.; Fukaki, H.; Ishizaki, K.; Goh, T.; Fukao, Y.; Sano, R.; Kurata, T.; Demura, T.; et al. Chloroplastic ATP synthase builds up a proton motive force preventing production of reactive oxygen species in photosystem I. Plant J. 2017, 91, 306-324. [CrossRef] [PubMed]

54. Kanazawa, A.; Ostendorf, E.; Kohzuma, K.; Hoh, D.; Strand, D.D.; Sato-Cruz, M.; Savage, L.; Cruz, J.A.; Fisher, N.; Froehlich, J.E.; et al. Chloroplast ATP Synthase Modulation of the Thylakoid Proton Motive Force: Implications for Photosystem I and Photosystem II Photoprotection. Front. Plant Sci. 2017, 8, 719. [CrossRef] [PubMed]

55. Huang, W.; Yang, Y.-J.; Zhang, S.-B. The role of water-water cycle in regulating the redox state of photosystem I under fluctuating light. Biochim. Biophys. Acta-Bioenerg. 2019, 1860, 383-390. [CrossRef]

56. Yang, Y.-J.; Tan, S.-L.; Huang, J.-L.; Zhang, S.-B.; Huang, W. The water-water cycle facilitates photosynthetic regulation under fluctuating light in the epiphytic orchid Dendrobium officinale. Environ. Exp. Bot. 2020, 180, 104238. [CrossRef]

57. Yang, Y.-J.; Zhang, S.-B.; Wang, J.-H.; Huang, W. Photosynthetic regulation under fluctuating light in field-grown Cerasus cerasoides: A comparison of young and mature leaves. Biochim. Biophys. Acta-Bioenerg. 2019, 1860, 148073. [CrossRef]

58. Tan, S.-L.; Huang, J.-L.; Zhang, F.-P.; Zhang, S.-B.; Huang, W. Photosystem I photoinhibition induced by fluctuating light depends on background low light irradiance. Environ. Exp. Bot. 2021, 181, 104298. [CrossRef]

59. Kono, M.; Yamori, W.; Suzuki, Y.; Terashima, I. Photoprotection of PSI by far-red light against the fluctuating light-induced photoinhibition in Arabidopsis thaliana and field-grown plants. Plant Cell Physiol. 2017, 58, 35-45. [CrossRef] [PubMed]

60. Tiwari, A.; Mamedov, F.; Grieco, M.; Suorsa, M.; Jajoo, A.; Styring, S.; Tikkanen, M.; Aro, E.-M. Photodamage of iron-sulphur clusters in photosystem I induces non-photochemical energy dissipation. Nat. Plants 2016, 2, 16035. [CrossRef]

61. Tikkanen, M.; Aro, E.M. Integrative regulatory network of plant thylakoid energy transduction. Trends Plant Sci. 2014, 19, 10-17. [CrossRef] [PubMed]

62. Munekage, Y.; Hojo, M.; Meurer, J.; Endo, T.; Tasaka, M.; Shikanai, T. PGR5 is involved in cyclic electron flow around photosystem I and is essential for photoprotection in Arabidopsis. Cell 2002, 110, 361-371. [CrossRef]

63. Tikkanen, M.; Mekala, N.R.; Aro, E.-M. Photosystem II photoinhibition-repair cycle protects Photosystem I from irreversible damage. Biochim. Biophys. Acta-Bioenerg. 2014, 1837, 210-215. [CrossRef] [PubMed]

64. Nakano, H.; Yamamoto, H.; Shikanai, T. Contribution of NDH-dependent cyclic electron transport around photosystem I to the generation of proton motive force in the weak mutant allele of pgr5. Biochim. Biophys. Acta-Bioenerg. 2019, 1860, 369-374 [CrossRef]

65. Huang, W.; Sun, H.; Tan, S.-L.; Zhang, S.-B. The water-water cycle is not a major alternative sink in fluctuating light at chilling temperature. Plant Sci. 2021, 305, 110828. [CrossRef] [PubMed]

66. Yang, Y.-J.; Sun, H.; Zhang, S.-B.; Huang, W. Roles of alternative electron flows in response to excess light in Ginkgo biloba. Plant Sci. 2021, 312, 111030. [CrossRef]

67. Sun, H.; Shi, Q.; Zhang, S.-B.; Huang, W. Coordination of Cyclic Electron Flow and Water-Water Cycle Facilitates Photoprotection under Fluctuating Light and Temperature Stress in the Epiphytic Orchid Dendrobium officinale. Plants 2021, 10, 606. [CrossRef]

68. Sun, H.; Yang, Y.-J.; Huang, W. The water-water cycle is more effective in regulating redox state of photosystem I under fluctuating light than cyclic electron transport. Biochim. Biophys. Acta-Bioenerg. 2020, 1861, 148235. [CrossRef] [PubMed]

69. Yang, Y.-J.; Tan, S.-L.; Sun, H.; Huang, J.-L.; Huang, W.; Zhang, S.-B. Photosystem I is tolerant to fluctuating light under moderate heat stress in two orchids Dendrobium officinale and Bletilla striata. Plant Sci. 2021, 303, 110795. [CrossRef]

70. Huang, W.; Hu, H.; Zhang, S.B. Photosynthetic regulation under fluctuating light at chilling temperature in evergreen and deciduous tree species. J. Photochem. Photobiol. B Biol. 2021, 219, 112203. [CrossRef] [PubMed]

71. Bauwe, H.; Hagemann, M.; Kern, R.; Timm, S. Photorespiration has a dual origin and manifold links to central metabolism. Curr. Opin. Plant Biol. 2012, 15, 269-275. [CrossRef] [PubMed]

72. Anderson, L.E. Chloroplast and cytoplasmic enzymes II. Pea leaf triose phosphate isomerases. Biochim. Biophys. Acta-Enzymol. 1971, 235, 237-244. [CrossRef]

73. Kelly, G.J.; Latzko, E. Inhibition of spinach-leaf phosphofructokinase by 2-phosphoglycollate. FEBS Lett. 1976, 68, 55-58. [CrossRef]

74. Flügel, F.; Timm, S.; Arrivault, S.; Florian, A.; Stitt, M.; Fernie, A.R.; Bauwe, H. The photorespiratory metabolite 2-phosphoglycolate regulates photosynthesis and starch accumulation in Arabidopsis. Plant Cell. 2017, 29, 2537-2551. [CrossRef] [PubMed] 
75. Hagemann, M.; Kern, R.; Maurino, V.G.; Hanson, D.T.; Weber, A.P.M.; Sage, R.F.; Bauwe, H. Evolution of photorespiration from cyanobacteria to land plants, considering protein phylogenies and acquisition of carbon concentrating mechanisms. J. Exp. Bot. 2016, 67, 2963-2976. [CrossRef] [PubMed]

76. Eisenhut, M.; Ruth, W.; Haimovich, M.; Bauwe, H.; Kaplan, A.; Hagemann, M. The photorespiratory glycolate metabolism is essential for cyanobacteria and might have been conveyed endosymbiontically to plants. Proc. Natl. Acad. Sci. USA 2008, 105, 17199-17204. [CrossRef]

77. Timm, S.; Wittmiß, M.; Gamlien, S.; Ewald, R.; Florian, A.; Frank, M.; Wirtz, M.; Hell, R.; Fernie, A.R.; Bauwe, H. Mitochondrial dihydrolipoyl dehydrogenase activity shapes photosynthesis and photorespiration of Arabidopsis thaliana. Plant Cell 2015, 27, 1968-1984. [CrossRef]

78. Timm, S.; Florian, A.; Fernie, A.R.; Bauwe, H. The regulatory interplay between photorespiration and photosynthesis. J. Exp. Bot. 2016, 67, 2923-2929. [CrossRef] [PubMed]

79. South, P.F.; Cavanagh, A.P.; Liu, H.W.; Ort, D.R. Synthetic glycolate metabolism pathways stimulate crop growth and productivity in the field. Science 2019, 363, eaat9077. [CrossRef] [PubMed]

80. Yamori, W.; Makino, A.; Shikanai, T. A physiological role of cyclic electron transport around photosystem I in sustaining photosynthesis under fluctuating light in rice. Sci. Rep. 2016, 6, 20147. [CrossRef] [PubMed]

81. Nawrocki, W.J.; Bailleul, B.; Cardol, P.; Rappaport, F.; Wollman, F.A.; Joliot, P. Maximal cyclic electron flow rate is independent of PGRL1 in Chlamydomonas. Biochim. Biophys. Acta-Bioenerg. 2019, 1860, 425-432. [CrossRef] [PubMed]

82. Nawrocki, W.J.; Bailleul, B.; Picot, D.; Cardol, P.; Rappaport, F.; Wollman, F.A.; Joliot, P. The mechanism of cyclic electron flow, Biochim. Biophys. Acta-Bioenerg. 2019, 1860, 433-438. [CrossRef] [PubMed]

83. Fisher, N.; Bricker, T.M.; Kramer, D.M. Regulation of photosynthetic cyclic electron flow pathways by adenylate status in higher plant chloroplasts. Biochim. Biophys. Acta-Bioenerg. 2019, 1860, 148081. [CrossRef] [PubMed]

84. Takahashi, S.; Milward, S.E.; Fan, D.-Y.; Chow, W.S.; Badger, M.R. How Does Cyclic Electron Flow Alleviate Photoinhibition in Arabidopsis? Plant Physiol. 2009, 149, 1560-1567. [CrossRef] [PubMed]

85. Lima-Melo, Y.; Gollan, P.J.; Tikkanen, M.; Silveira, J.A.G.; Aro, E.M. Consequences of photosystem-I damage and repair on photosynthesis and carbon use in Arabidopsis thaliana. Plant J. 2019, 97, 1061-1072. [CrossRef] [PubMed] 